W34 in

No. S-73-20

Cop. 3

$U S=C-C$ Property of the United States Government

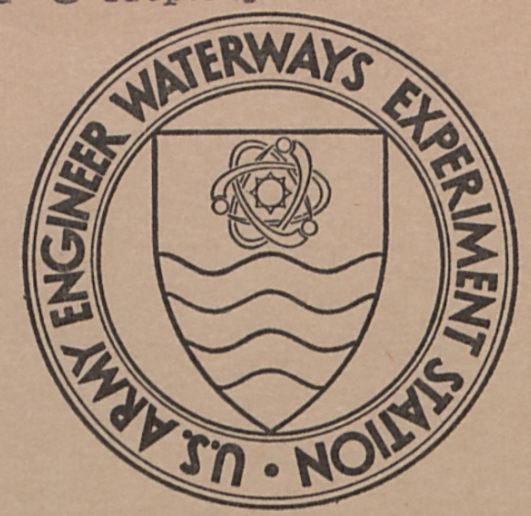

MISCELLANEOUS PAPER S-73-20

\title{
RAYLEIGH-WAVE DISPERSION TECHNIQUE FOR RAPID SUBSURFACE EXPLORATION
}

by

F. K. Chang, R. F. Ballard, Jr.
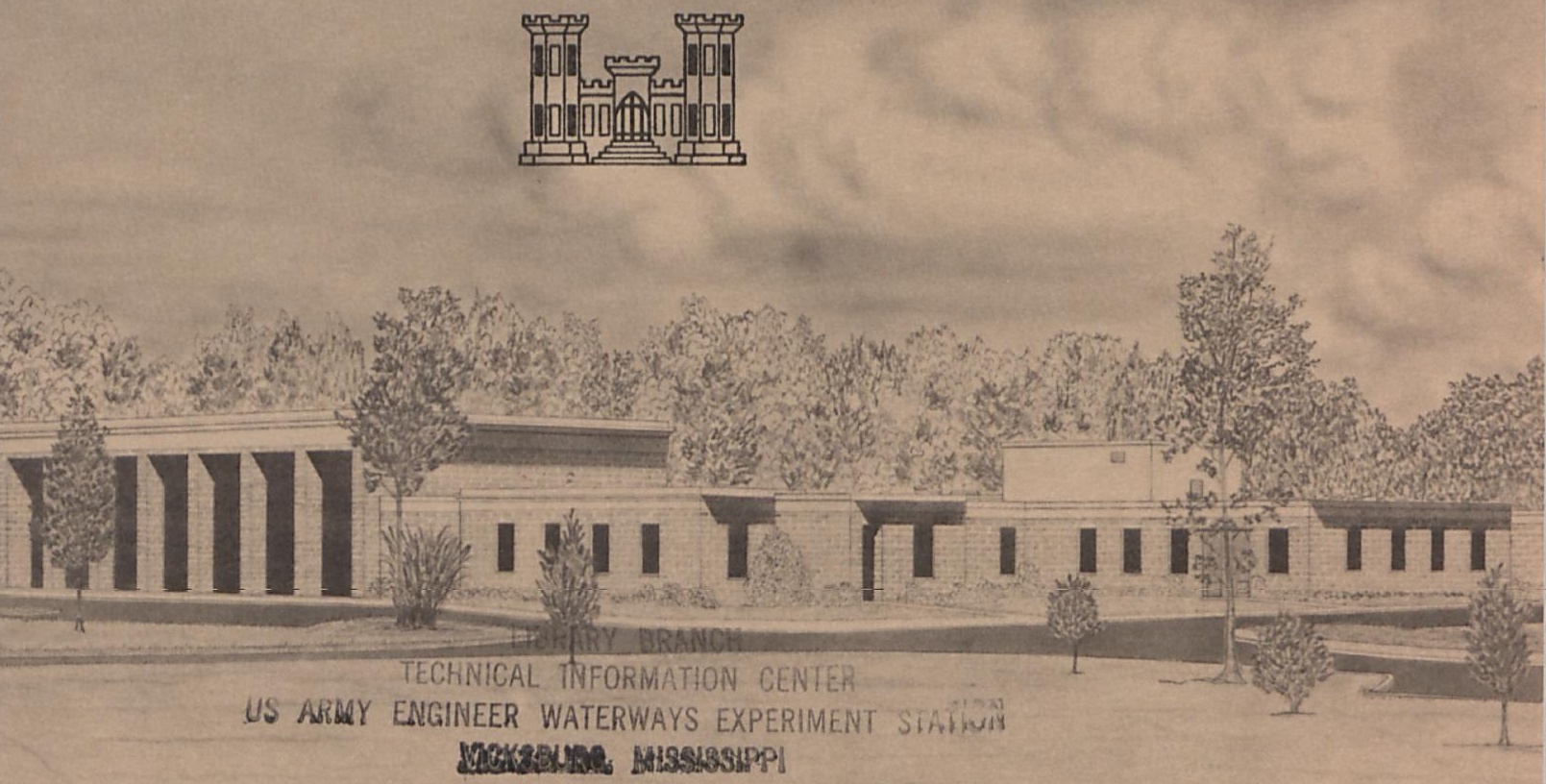

April 1973

Published by U. S. Army Engineer Waterways Experiment Station

Soils and Pavements Laboratory

Vicksburg, Mississippi 


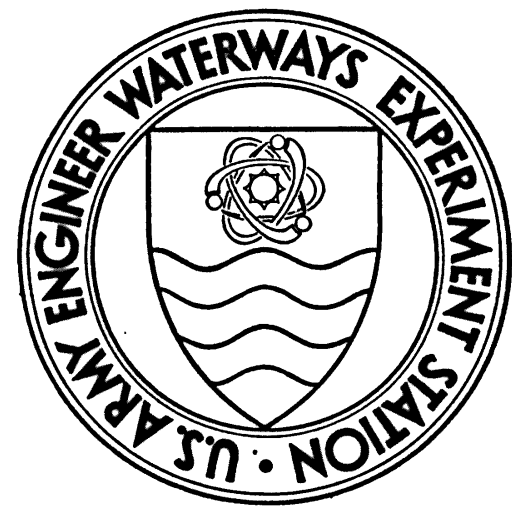

MISCELLANEOUS PAPER S-73-20

\section{RAYLEIGH-WAVE DISPERSION TECHNIQUE FOR RAPID SUBSURFACE EXPLORATION \\ by \\ F. K. Chang, R. F. Ballard, Jr.}

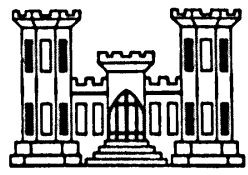

April 1973

Published by U. S. Army Engineer Waterways Experiment Station

Soils and Pavements Laboratory

Vicksburg, Mississippi 
FOREWORD

This report is a paper that was presented to the 42nd Annual International Meeting of the Soclety of Exploration Geophysicists. The investigation that generated the information used in the paper was assigned as a work unit, "Techniques for Rapid Subsurface Exploration," of an RDT\&E Project, "Permanent Construction Materials and Techniques for FY 70." This report is an interim report; a final report will be published in FY 74 .

Engineers of the U. S. Army Engineer Waterways Experiment Station (WES) who were actively engaged in the investigation, analysis, and report phases of this study were Messrs. R. W. Cunny, Z. B. Fry, R. F. Ballard, and F. K. Chang, of the Solls and Pavements Laboratory (S\&PL). The work was performed during the period December 1969 through March 1972 under the general supervision of Mr. J. P. Sale, Chief, S\&PL. The paper was prepared by Messrs. Ballard and Chang.

COL Levi A. Brown, CE, and COL Ernest D. Peixotto, CE, were Directors of WES during the conduct of the investigation and publication of this report. Mr. F. R. Brown was Technical Director. 
CONTENTS

FOREWORD ...................... $\frac{\text { Page }}{i i i}$

CONVERSION FACTORS, BRITISH TO METRIC UNITS OF

MEASUREMENT .................. . . vii

ABSTRACT . . . . . . . . . . . . . . $\quad i x$

INTRODUCTION . . . . . . . . . . . . . . I I

Purpose and Scope ................ . I

Background ................. 1

RAYLEIGH-WAVE DISPERSION TECHNIQUE . . . . . . . 5

Field Procedure . . . . . . . . . . . 6

Data Interpretation ............. 7

Seismogram Analyses ............. . 8

Evaluation ................. 21

CONCLUSIONS . . . . . . . . . . . . 23

REFERENCES 
CONVERSION FACTORS, BRITISH TO METRIC UNITS OF MEASUREMENT

British units of measurement used in this report can be converted to metric units as follows:

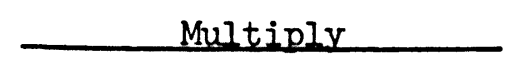

feet

pounds

pounds per square inch

pounds per cubic foot

feet per second
$\mathrm{By}$

0.3048

0.45359237

0.070307

16.0185

0.3048
To Obtain

meters

kilograms

kilograms per square centimeter

kilograms per cubic centimeter

meters per second 
Rayleigh-Wave Dispersion Technique

for

Rapid Subsurface Exploration

F. K. Chang* and R. F. Ballard, Jr.**

This paper reports an investigation of improved or new techniques to extend the depth and/or resolution capability of rapid shallow-depth (less than $500 \mathrm{ft}$ ) explorations that would quickly and economically provide an engineer with accurate information on substrate conditions. Current geophysical techniques for rapidly exploring construction sites and investigating foundations, i.e., electrical resistivity, seismic refraction, and vibratory techniques, were reviewed for relative merits and shortcomings. By combining various attributes of the refraction seismic and vibratory techniques, it was considered feasible that a study of surface-wave phenomena could measurably extend the depth limits of current investigation techniques. As a result, the so-called "Rayleigh-wave dispersion technique" was envisioned as a potentially

\footnotetext{
* U. S. Army Engineer Waterways Experiment Station, Soils and-Pavements Laboratory, Corps of Engineers, Vicksburg, Mississippi. Engineer, Earthquake Engineering and Vibrations Division.

** U. S. Army Engineer Waterways Experiment Station, Soils and Pavements Laboratory, Corps of Engineers, Vicksburg, Mississippi. Chief, Geodynamics Branch.
} 
promising, in situ test method.

A test program was formulated to adapt conventional refraction seismic equipment and field procedures to acquire Rayleighwave data. Theoretical considerations, test procedures, interpretation of data, and comparisons with data obtained by standard methods are presented. Various advantages and limitations of the Rayleighwave dispersion technique are discussed. 


\section{Purpose and Scope}

The purposes of the study from which this paper was compiled were to review rapid subsurface exploration techniques currently employed to provide engineering information on subsurface geological formations that may be used as foundation or construction materials, and to investigate alternate or supplemental techniques as improved tools for rapid subsurface exploration (Ballard and Chang, 1973). The scope of this paper involves a cursory review of existing rapid, reliable, low-cost geophysical methods for site investigation and location of construction materials, as well as a detailed description of a new Rayleigh-wave dispersion technique for improvement of existing rapid exploration capabilities.

\section{Background}

The strength, compressibility, and permeability properties of soils or rocks usually control the design of foundations. During preliminary site or foundation investigations, rapid means of indirectly determining these properties or indexes to the properties and general stratification over Iarge areas are desired. During later phases of the investigations at particular sites, more detailed or specific descriptions of the foundation materials are desired. The subsurface exploration techniques used to determine the desired properties of the material can be divided into 
indirect and direct techniques (Glossop, 1968). Indirect techniques

In geophysical techniques for shallow-depth exploration (maximum depth to bedrock $\simeq 500 \mathrm{ft}$ ), the seismic refraction and the electrical resistivity techniques are comonly used (Dorbrin, 1968, and Heiland, 1940). The depth as well as the velocity of subsurface materials can be directly determined by a seismic refraction sounding; the dynamic confined compression modulus of elasticity can be calculated from the velocity if the density of the material is known or can be estimated. The electrical resistivity technique is used to detect the variation in resistivity of earth materials, which is largely dependent upon the amount and salinity of the contained water; thus, indirect measurements of porosity, saturation, and permeability are possible. The seismic refraction and resistivity techniques each have certain advantages and disadvantages as exploration tools. Sometimes the two techniques complement each other for certain types of subsurface investigations, so that it may be very advantageous to use both as a means of achieving speed, economy, and reliability: I'en years ago, the U. S. Army Engineer Waterways Experiment Station (WES) adopted a combination of a vibratory technique in conjunction with the seismic refraction technique to determine the in situ shear and Young's elastic moduli of soils (Fry, 1963). The vibratory and selsmic refraction techniques were used to measure the Rayleighand compression-wave velocities of soils, respectively. The 
gravitational and magnetic techniques, generally used for the study of regional geological structure, are without depth control and have little significant engineering value.

The general advantages of the indirect techniques are:

a. Geophysical techniques of exploration identify gross changes in character of subsurface materials by surface measurement of the changes in certain physical properties of the earth at or near its surface.

b. Larger areas or projects of greater linear extent can be explored more rapidly and economically by use of geophysical techniques than by use of borings.

c. The surface measurements as determined by use of these techniques indicate average conditions within a limited area and not along a single vertical or inclined line, such as is the case when the boring technique is used.

d. Data acquired by use of these techniques can be used to detect the subsurface irregularities that often are missed by borings.

The disadvantages are:

a. Although the general character of subsurface materials can often be estimated, the materials cannot be definitely identified by geophysical techniques alone; therefore, these techniques must be supplemented by borings in which representative and/or undisturbed samples are obtained. 
b. The interpretation of geophysical data requires trained and experienced personnel.

Geophysical techniques are, however, especially well suited for reconnaissance and preliminary determination of formation conditions of large areas to be used in the construction of missile sites, military underground structures, nuclear reactors, dams and reservoirs, tunnels, highways, airfields, large housing projects, etc. Geophysical techniques have also been used successfully for the determination of water tables and deposits of gravel or other engineering construction materials.

\section{Direct techniques}

The conventional or direct techniques utilized for subsurface exploration and determination of foundation properties include boring; sampling, measurements of penetration resistance, vaneshear strength, plate-bearing capacity, and California Bearing Ratio; and other special purpose tests and the conduct of desired laboratory tests on disturbed or undisturbed samples as the situation requires. The direct techniques of exploration are relatively slow and expensive and are not discussed further in this paper. The authors feel that the thrust of this paper should be directed toward a description of the Rayleigh-wave dispersion technique as a potential new tool for rapid subsurface exploration rather than discussing "yesterday's newspaper." 
It is generally understood that the conventional seismic refraction technique will provide a compression-wave velocity and an accurate depth determination from the first arrival times of compression waves, and that the shear-wave velocity at depth can be determined by the vibratory technique, which has a limited depth of penetration of about 150-200 ft. Shear modulus, Poisson's ratio, and Young's modulus can be calculated by using the compression- and shear-wave velocities and the mass density of the soil or rock.

Through analyses of data acquired using the vibratory technique, it has been found that the waves produced by the vibrator are predominantly Rayleigh waves. It is considered feasible to explore shallow depth by means of Rayleigh waves generated by refraction seismic tests for the following reasons:

a. Rayleigh waves as well as compression waves are generated by the refraction seismic tests.

b. Rayleigh waves are more easily observed than shear waves.

c. A pulse traveling with Rayleigh-wave velocity should be a prominent feature on any seismic refraction record unless the instrumentation has been designed specifically to reject it. .

d. Rayleigh waves generated by earthquakes have been used successfully as a tool for exploration of the earth's 
crust and mantle structure during the past three decades.

In view of the reasons mentioned above, a proposed seismic refraction test procedure and a plan of test to record the compression wave, shear wave, and Rayleigh wave on the same seismogram have been considered. Certain preliminary tests have been conducted for comparison of Rayleigh-wave velocities determined with both vibratory and refraction seismic techniques.

\section{Field Procedure}

The field procedure for recording the Rayleigh or R-waves during refraction seismic tests is as simple as that for recording the compression or P-waves. Actually, the P- and R-waves can be recorded on the same seismogram following one shot if the instrumentation incorporates specially designed automatic gain control (AGC) circuitry. Considering that a sharply breaking, large-amplitude, first arrival P-wave is necessary, two shots must be made with less sophisticated instrumentation: one using a large amount of TNT ( 3 to 5 lb) for recording P-waves, and one using a lesser amount of TNT ( 0.25 to $2 \mathrm{lb})$ for recording R-waves. The size of the charge depends on the shot-to-detector distance. At a close shot distance of $10 \mathrm{ft}$, an electrical cap may be sufficient.

For routine dynamic foundation studies, a twelve-geophone seismic cable with 25-ft spacing of the geophones is sufficient. 
In practice, shots are fired at increasing distances from each end of the cable spread until seismic waves from the bedrock are recorded on an oscillograph. For rapid reconnaissance in a large area, a twelve-geophone seismic cable with geophones at 50-ft intervals can be used. For rapid subsurface exploration, two seismic profiles of fairly long length perpendicular to each other can usually be completed within two days.

The instrumentation system employed in field explorations is similar in most respects to that used in shallow refraction explorations. The band of frequency response including the geophone amplifier and galvanometer is wider (around the range of 2 to $200 \mathrm{~Hz}$ ) than in standard seismic equipment. The geophones are of the velocity type and especially designed for low-frequency measurement. Present WES recording seismic instruments were adapted for the purpose of conducting the field experiments.

\section{Data Interpretation}

Definitions of the group and phase velocities

To analyze the dispersion characteristics of an R-wave, the group or phase velocities of several frequency components of the R-wave must be measured. The group velocity can be measured by assuming that the wave originates as a sharp pulse at the instant of the shot and at the surface directly above the shot point. On this assumption, Grant and West (1965) determined that the group 
velocity $v_{g}$ for a travel time $t$ of a particular cycle of period $T$ observed at the minimum horizontal distance $X$ from the shot is given by

$$
v_{g}=\frac{x}{t}
$$

In the case of soil deposits, the seismic-wave velocities increase with depth, and the group velocity is generally less than the phase velocity. The phase velocity can be found by numbering the peaks and troughs of the oscillations and following them from one adjacent trace to the next as will later be described in detail. Assuming that the period of a given cycle in the sequence does not change drastically from one trace to the next, the Rayleigh phase velccity or Rayleigh-wave velocity $\mathrm{v}_{r}$ can be approximated by the relationship given by Grant and West (1965),

$$
v_{r}=\frac{\Delta X}{\Delta t},
$$

where $\Delta \mathrm{X}$ is the distance between adjacent seismometers and $\Delta t$ is the apparent time required for the R-wave to travel this distance. (See Figure la for graphic representation of the quantities.)

\section{Seismogram Analyses}

Figure $\mathrm{lb}$ is a seismic record which has been idealized to show the prominent wave arrivals at two adjacent detector locations so that the R-wave anaiysis could be better illustrated. 


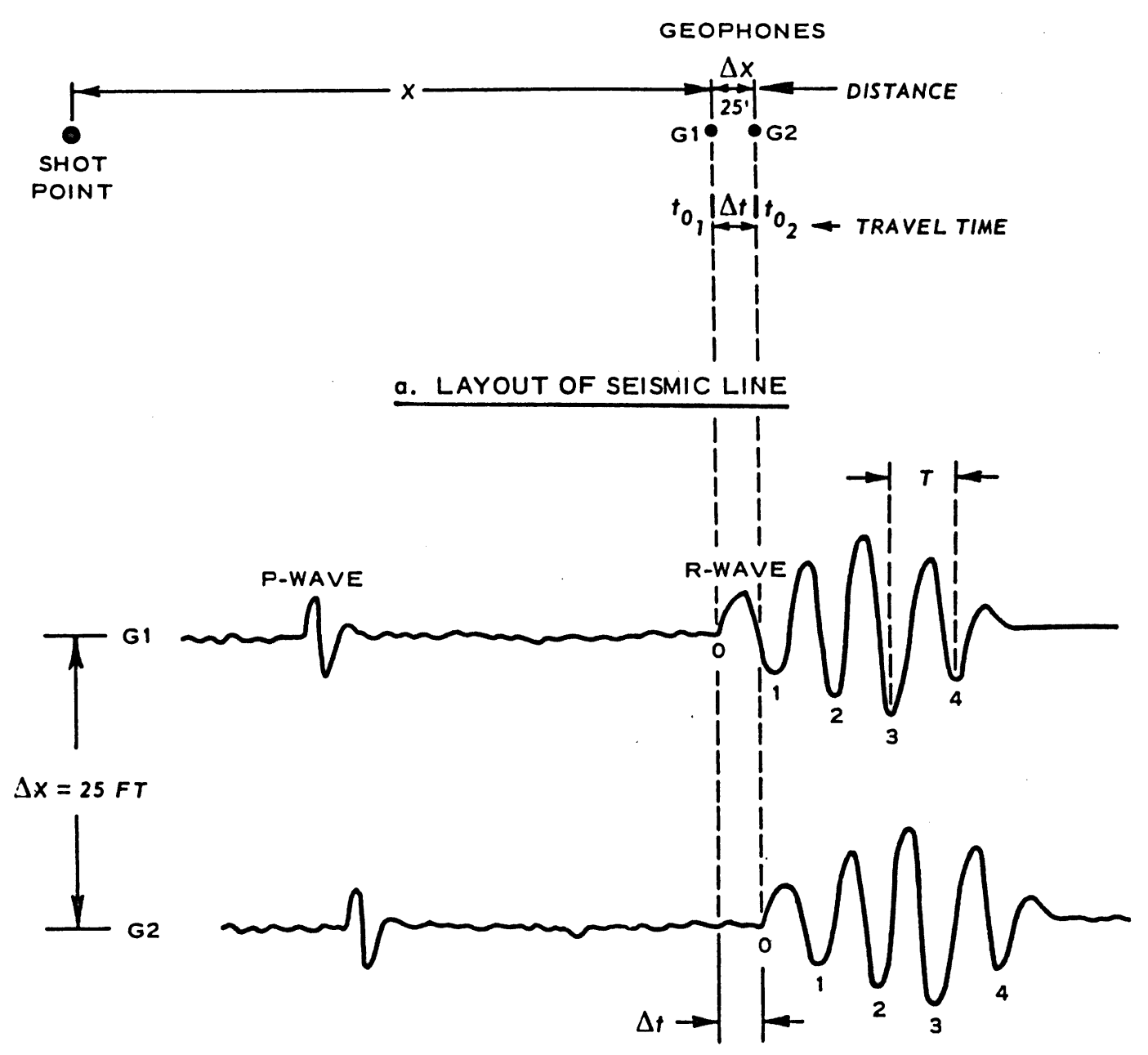

b. IDEALIZED SEISMIC RECORD

DEFINITIONS (IN ORDER OF APPEARANCE OR USE):

$X=$ HORIZONTAL DISTANCE OF SHOT POINT TO FIRST GEOPHONE $G 1$

$\triangle X=$ HORIZONTAL DISTANCE BETWEEN GEOPHONES G1 AND G2

$t=$ RAYLEIGH-WAVE ARRIVAL TIME (SUBSCRIPT $O=$ FIRST ARRIVAL, SUB-SUBSCRIPTS 1 AND 2 = GEOPHONE NUMBERS)

$\triangle t=$ APPARENT TIME REQUIRED FOR R-WAVE TO TRAVEL $\triangle X$ DISTANCE $0,1,2,3,4=$ SUCCESSIVE TROUGHS-OF RAYLEIGH WAVE TRAIN

$T=A V E R A G E$ PERIOD

$v_{r}=$ RAYLEIGH-WAVE VELOCITY OR $v_{p}=\frac{\Delta X}{\Delta t}$

$L=$ WAVELENGTH OR $L=v_{r} T$

$v_{g}=$ GROUP VELOCIT.Y OR $v_{g}=\frac{x}{t}$

Fig. 1. Layout of a typical seismic line and an idealized seismic record 
To construct R-wave dispersion curves of phase and group velocity, the following steps must be undertaken:

Phase velocity

a. Number the crests or troughs of the Rayleigh-wave train for all traces.

b. Read time of arrival for each crest (or trough) and the average period $T$ for each trace.

c. Compute the incremental time $\Delta t$ between adjacent traces.

d. Determine the Rayleigh phase velocity $v_{r}$ for each wave number by $v_{r}=\frac{\Delta X}{\Delta t}$ where $\Delta X=$ distance between adjacent seismometers.

e. Compute the wavelength I for éach wave number by $L=v_{r} T$.

f. Tabulate data.

g. Plot $v_{r}$ as a function of $L$ or approximate depth, $L / 2$. Group velocity

a. Number the crests or troughs of the Rayleigh-wave train for at least one trace.

b. Read time of arrival $t_{0}$ for each wave number and its period.

c. Determine group velocity $v_{g}$ for each wave number by

$$
v_{g}=\frac{x}{t_{0}}
$$

where $\mathrm{X}=$ shot-to-detector distance.

d. Plot $v_{g}$ as a function of $T$ or $L$ (since $L=v_{r} T$ ). 
Data presentation and reduction

Providing that terrain is relatively flat and background noise levels are sufficiently low, the oscillographic data presentation can be controlled in the field so that office interpretation time will be minimized. This can be accomplished by simply adjusting the galvanometer alignment so that each trace will be spaced in proportion to the distance between adjacent geophones. In this way, the interpreter may work directly from the field records if he so desires. The field data obtained at WES test site 2 (Figure 2) can be used to illustrate this and several other interesting points. As will be observed, data were recorded in four 225-ft, 12-trace segments from geophones that were spaced at 25-ft intervals. The size of the seismic impulse source ranged from electrical caps to $1 / 3 \mathrm{Ib}$ of $\mathrm{C}-4$ explosive charges. (The size of the charge was kept to an effective minimum so as not to deface the landscape.) As a means of positive R-wave identification, traces 1,2 , and 3 were the registrations of a transverse, radial, and vertical geophone, respectively, located at the first station of each of the four lines.

Utilizing the simultaneous relationship of the vertical and horizontal (radial) geophones, one can plot the trajectory of particle motion. Figure 3 shows the construction of these diagrams for far-field stations located from 250 to $700 \mathrm{ft}$ from the selsmic source. If we note that both upward vertical motion and outward radial motion will produce a downward deflection of the 


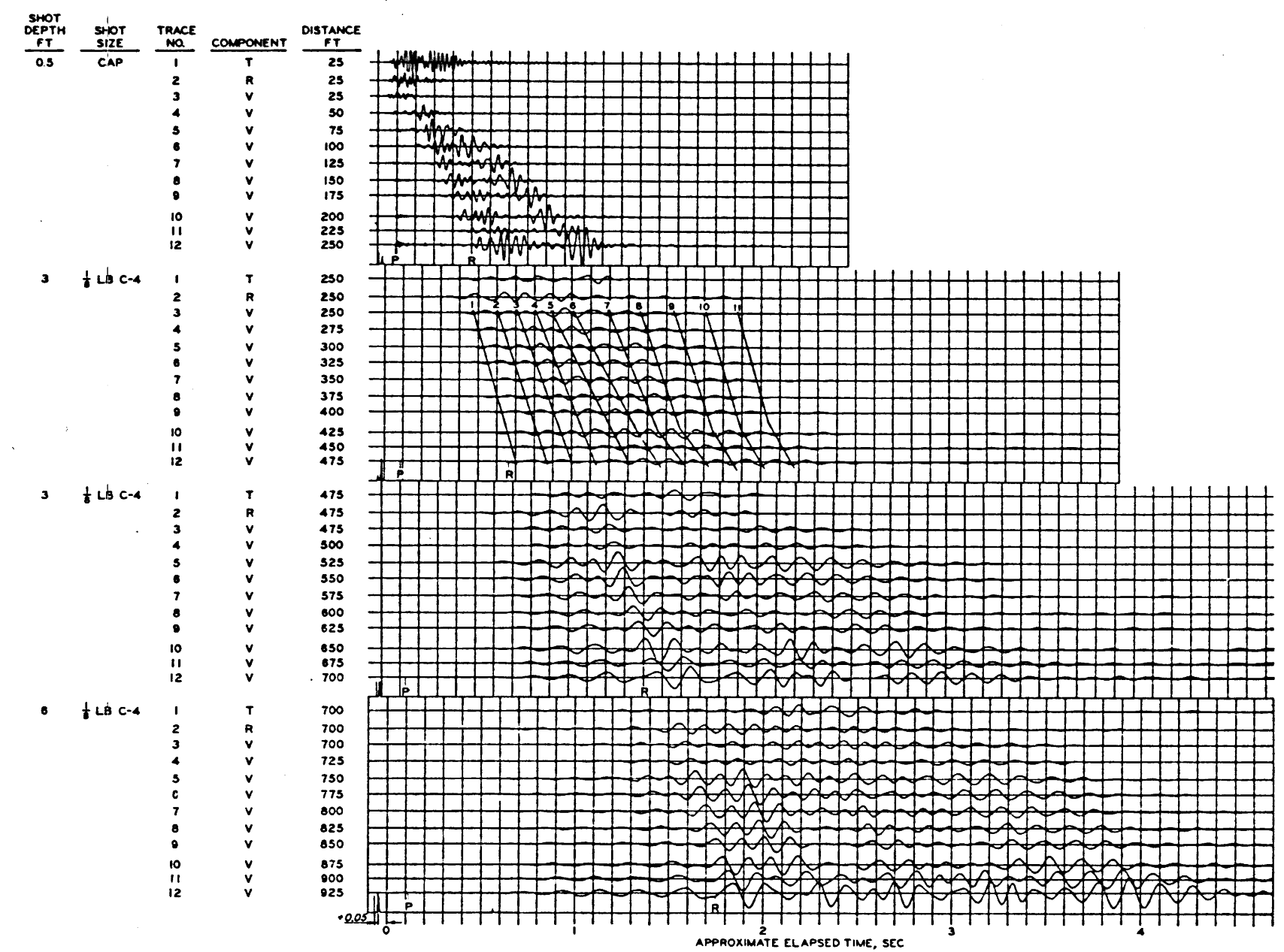

Fig. 2. R-wave dispersion profile (WES test site 2) 

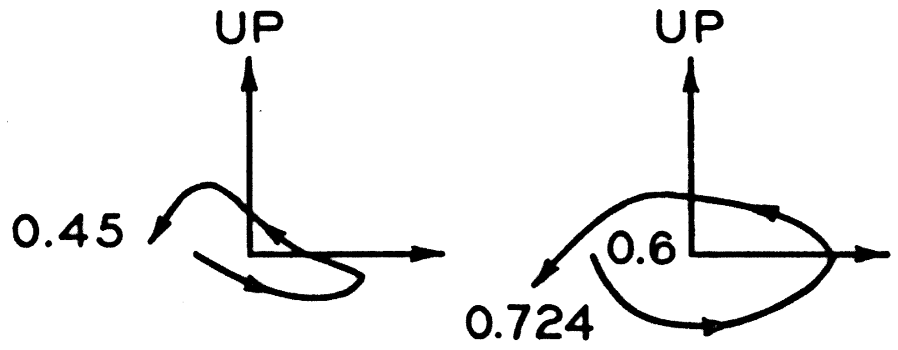

a. $250 \mathrm{FT}$ FROM SOURCE

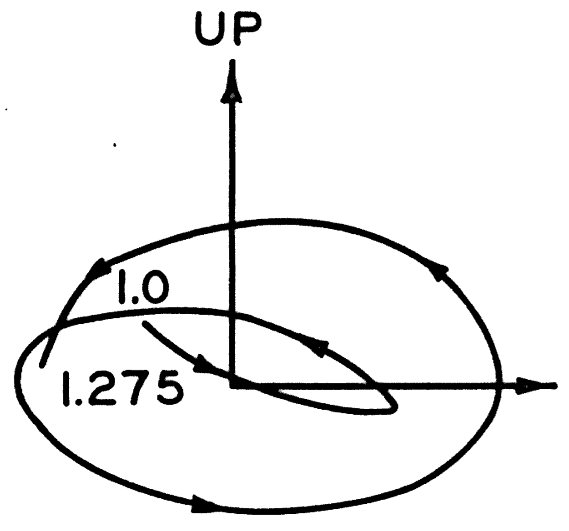

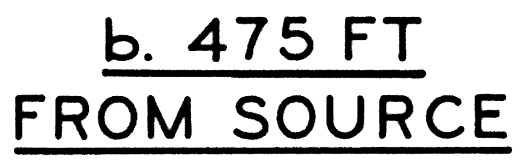

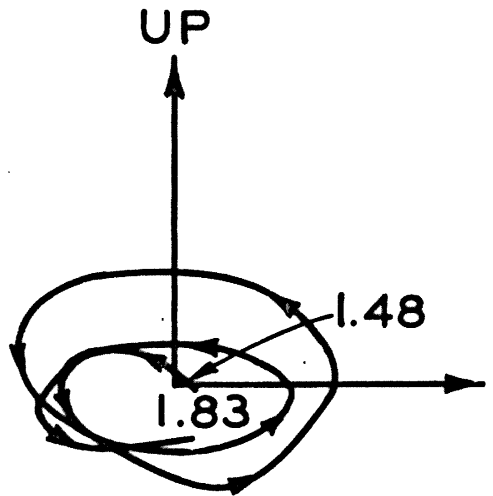

$\frac{\text { c. } 700 \mathrm{FT}}{\text { FROM SOURCE }}$

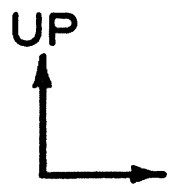

LEGEND

0.45 THAE IN SEC DIAGRAM WAS

EXTRACTED FROM RECORD

Fig. 3. Particle-motion diagrams for R-waves

(WES test site 2) 
seismogram trace, one should expect oscillations on the radial trace to lead those on the vertical trace by 90 degrees in phase. This is seen to be approximately true for those events labeled Rayleigh waves on the record shown in Figure 2. Earlier portions of the record do not show this phase shift due to direct, reflected, and refracted body waves causing distortion (Grant and West, 1965). In each of the three cases, the particle motion roughly takes the shape of a retrograde elliptical orbit, thus fulfilling the definition requirements for classical R-waves.

Observing the first or near-field record shown in Figure 2, one can readily see that the trace signature characteristics are completely different from the far-field records. This can possibly be explained by the fact that the distance between the shot and the geophones was less than the longest wavelengths that were observed at the far-field stations; therefore, the geophone spread is too close to observe dispersion. However, a second factor must also be considered; the seismic source for the near-field record was a single electrical cap buried only 0.5-ft deep. This source very likely possessed insufficient energy to excite the lower frequencies associated with depth penetration and consequently -greater soil masses.

As previously stated, interpretation can be performed directly on the records if so desired. For example, consider the second record in Figure $2(250-475 \mathrm{ft})$ for illustrative purposes. Beginning with trace 3 , some 11 distinct oscillations can be 
observed, numbered, and followed through the succeeding traces on the record. A line connecting adjacent troughs can then be constructed in a manner analogous to a conventional time-distance plot. Essentially, the reciprocal slope of this line will yield the wave velocity. An average period should then be determined so that the wavelength can be computed and plotted in the manner previously described.

Conversion of wave velocities to soil properties

To become a useful tool in terms of conventional soil properties, the P- and shear- or S-wave velocities determined by the above method must be related to elastic parameters such as shear modulus G, Young's modulus E, and Poisson's ratio $v$. This conversion can readily be accomplished knowing that the wave velocity is dependent on the ratio of the elasticity of the medium to its mass density $\rho$ and on the wave type. The relationship of shear modulus $G$ and shear-wave velocity $v_{s}$ and density $\rho$ is as follows:

$$
G=v_{s}^{2} \rho
$$

S-wave velocity and surface R-wave velocity are related by Poisson's ratio. For a homogeneous medium and for Poisson's ratios ranging from 0.2 to 0.5 , the difference in velocities is less than 9 percent. Therefore, for practical purposes, S-waves can be considered to have the same velocity as R-waves.

Poisson's ratio $\nu$ of a soil can be determined by the relation of S-wave velocities $v_{s}$ and $P$-wave velocities $v_{c}$. 


$$
v=\frac{1-\left(2 \frac{v_{s}}{v_{c}}\right)^{2}}{2-\left(2 \frac{v_{s}}{v_{c}}\right)^{2}}
$$

Young's modulus $\mathrm{E}$ is related to shear modulus $\mathrm{G}$ and Poisson's ratio of the soil by

$$
E=2(I+v) G
$$

for isotropic, linearly elastic materials. From these equations, values of $E, G$, and $\nu$ can be determined through the measurement of S- and P-wave velocities, provided the density of the soil is known or can be estimated.

Heukelom and Foster (1960), in their dynamic testing of pavements using the vibratory technique, found that excellent correlations could be estimated with known depth of layers if they empirically assumed a measured velocity applicable at a depth equal to half its associated wavelength. During the past ten years, WES has extensively employed this empirical relationship for investigations where boring data were also available to determine depths of interfaces for different materials and agreement has generally been good; consequently, this relationship is assumed valid for the $R$-wave dispersion method.

Figure 4 is the R-wave velocity for WES test site 2 plotted as a function of depth ( $L / 2)$ prepared using the R-wave dispersion technique. In addition, data obtained by using the surface vibratory 


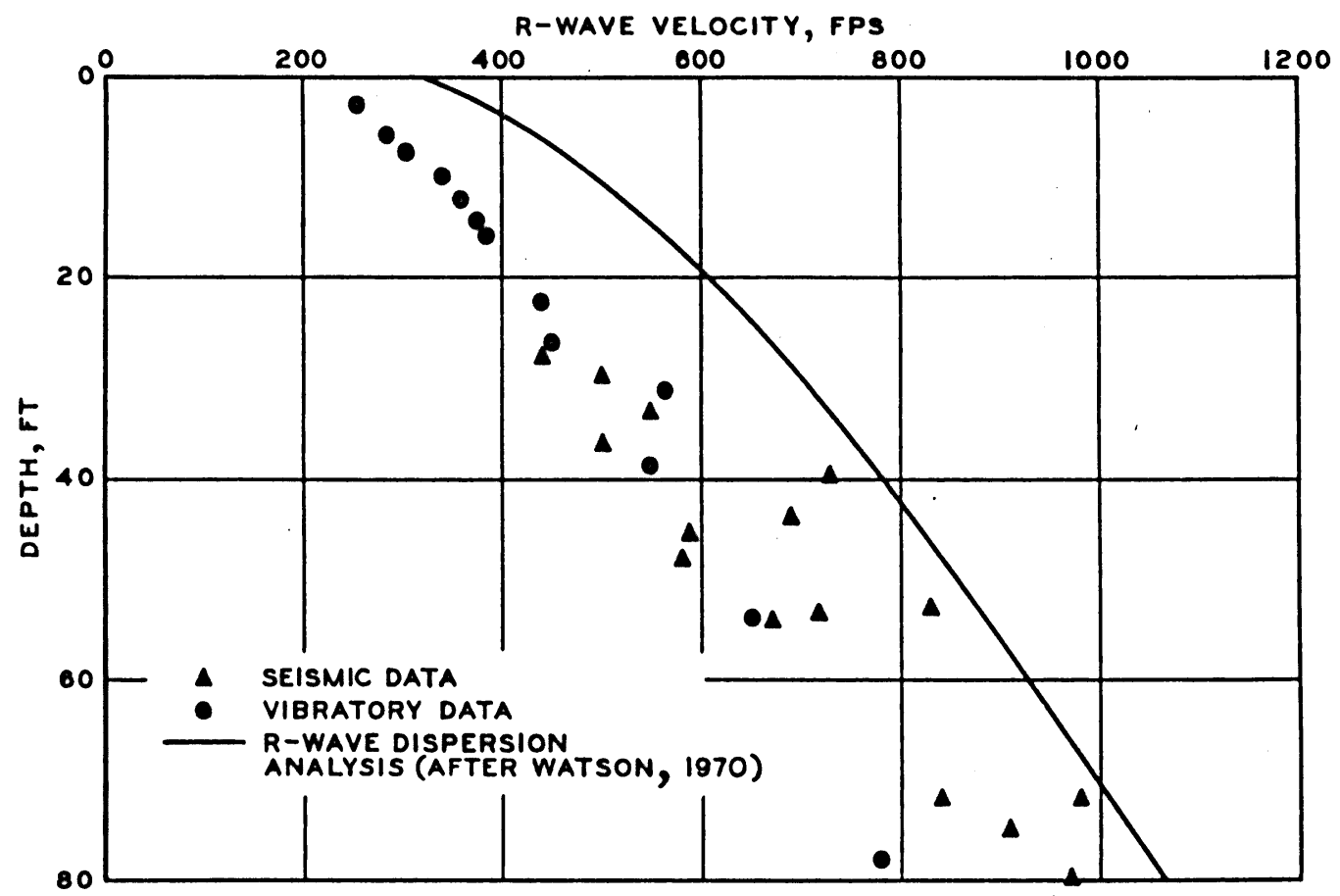

Fig. 4. R-wave velocity as a function of depth (WES test site 2) 
technique is shown for comparative purposes. It is interesting to note that excellent agreement exists between the vibratory and seismic methods to depths of about 40 or $50 \mathrm{ft}$; then the R-wave dispersion data diverges to indicate higher apparent velocities. This can possibly be explained by the fact that the earliest wave arrivals (generally the longest wavelengths) are a mixture of reflected $\mathrm{P}-, \mathrm{S}-$, and R-waves that tend to propagate at a higher apparent velocity. Unfortunately, the manual method of determining the phase velocity is seldom accurate enough, and it is generally necessary to make a Fourier analysis of each adjacent pair of traces and measure $\Delta t$ from the phase shift of the Fourier element whose period is $T$ (Grant and West, 1965). Such an analysis can be performed with available computer codes if it is considered necessary by the data user. A second possible explanation is the difference in stress levels generated by the two methods of testing. Though not as plausible as the first explanation, it must be considered as a possibility and further study must be made to document possible velocity changes as a function of source stress level. Once the elastic moduli have been determined, they may also be conveniently displayed as a function of depth. These data, which were obtained at the same WES test site, are shorm in Figure 5. Once these parameters are supplied to a knowledgeable designer, a structure with predictable performance can be designed (OCE, 1967). Another application for use of these soil parameters would be for a dynamic analysis of existing earthen structures such as dams 


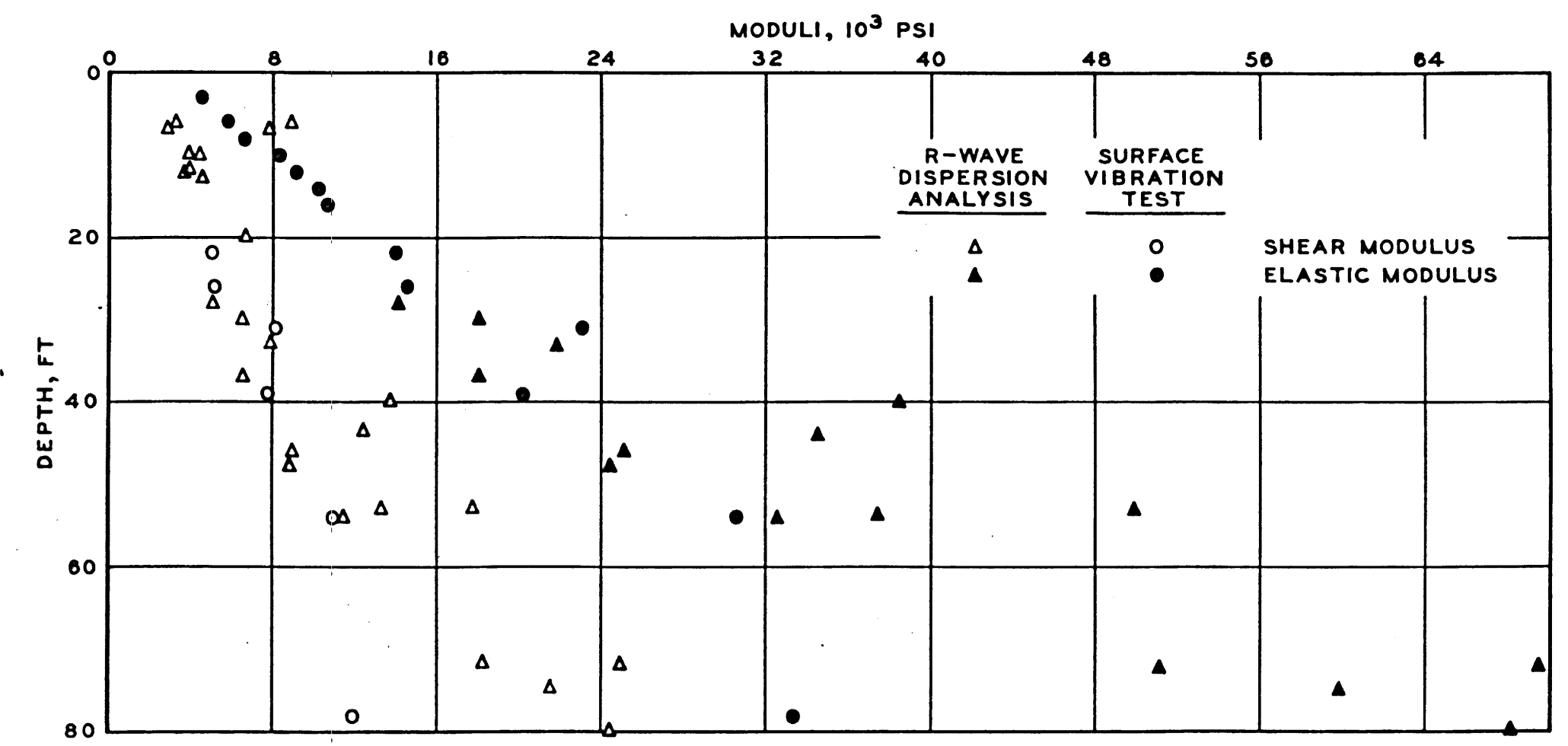

Fig. 5. Elastic and shear moduli as a function of depth (WES test site 2) 
potentially exposed to earthquake hazards.

Theoretical calculations

As a means of supplementing the interpretation of data obtained by the R-wave dispersion technique, comparisons with theoretical dispersion curves based on soil layering, P-wave velocity, S-wave velocity, and density of the media can be made. These parameters can be determined by borehole sampling, conventional seismic refraction, and some engineering estimates of material properties. Referring again to Figure 4, one can see the comparison of theoretical and experimental values. In this case, all three methods were used as an aid in establishing layer thickness and properties of the WES test site. The model chosen to represent this site was representative of a four-layer system. The following characteristics were assigned to each succeeding layer.

\begin{tabular}{|c|c|c|c|}
\hline \multirow{2}{*}{$\begin{array}{l}\text { Depth } \\
\mathrm{ft} \\
\end{array}$} & \multicolumn{2}{|c|}{ Velocity, fps } & \multirow{2}{*}{$\begin{array}{l}\text { Wet Density } \\
\text { pcf }\end{array}$} \\
\hline & P-Wave & S-Wave & \\
\hline $0-12$ & 1,110 & 350 & 116 \\
\hline $13-56$ & 5,000 & 650 & 122 \\
\hline $57-76$ & 5,000 & 980 & 126 \\
\hline $77-\infty$ & 10,000 & 4550 & $15 h_{t}$ \\
\hline
\end{tabular}

Utilizing these assigned descriptors in a R-wave dispersion computer code developed by Watson (1970), the theoretical fundamental mode for this test, which was treated as a four-layer problem, can be calculated. It is apparent from Figure 4 that 
some differences in absolute velocities do exist. Future research will seek to reconcile these differences.

\section{Evaluation}

The advantages and limitations of the R-wave dispersion technique are:

Advantages

a. R-waves are in most instances easily observed and should be prominent features on any seismic refraction record.

b. The computation of phase velocity of an R-wave is easy.

c. The R-wave dispersion technique is a combination of seismic refraction and vibratory techniques; thus, half of the field working time could be saved by using this technique. However, it must be stated that additional interpretation time spent in the office tends to minimize the overall cost savings.

\section{Limitations}

a. The investigation area must be large enough that adequate information can be obtained. For example, if the bedrock is $100 \mathrm{ft}$ deep, the length of the profile line (seismic-cable spread) should not be less than $500 \mathrm{ft}$.

b. Interpretation of the R-wave data requires the services of a competent, trained geophysicist.

c. The R-wave dispersion technique yields velocities that 
are consistently higher than those obtained by the surface vibratory technique and laboratory test methods. 


\section{CONCLUSIONS}

Preliminary field experiments indicate that the R-wave dispersion method for determining shear-wave velocity by surface measurements is indeed feasible, but certain questions need to be resolved. Most apparent is the lack of absolute correlation between data from that method and surface vibratory data. At certain test sites examined at this time, the R-wave dispersion method yielded consistently higher velocities at depths greater than $50 \mathrm{ft}$. Indications are that the discrepancy may be due to wave interference (model superposition on the actual seismograms) or possibly stress conditions at the source. However, additional study is needed to resolve these observed differences. 


\section{REFERENCES}

Ballard, R. F., Jr., and Chang, F. K., 1973, Rapid subsurface exploration: miscellaneous paper in publication, Vicksburg, Ms, U. S. Army Engineer Waterways Experiment Station, CE. Dorbrin, M. B., 1952, Introduction to geophysical prospecting: New York, McGraw-Hill.

Fry, Z. B., 1963, A procedure for determining elastic moduli of soils by field vibratory techniques: miscellaneous paper 4-577, Vicksburg, Ms, U. S. Army Engineer Waterways Experiment Station, CE. Glossop, R., 1968, The rise of geotechnology and its influence on engineering practice: Geotechnique, v. 18, no. 2, p. 146. Grant, F. S., and West, G. F., 1965, Interpretation theory in applied geophysics: New York, McGraw-Hill. Heiland, C. A., 1940, Geophysical exploration: New York, Prentice-Hall.

Heukelom, W., and Foster, C. R., 1960, Dynamic testing of pavements: Journal of soil mechanics and foundations division, A.S.C.E., v. 86, SMI, p. 1-28. Office, Chief of Engineers, 1967, Engineering and design, foundations subject to vibratory loads: EM 1110-345-310, Washington, D. C. Watson, T. H., 1970, A note on fast computation of rayleigh wave dispersion in the multilayered elastic half-space: Bull. S. S., v. 60, no. 1, p. 161-166. 
Unclassified

Security Classification

DOCUMENT CONTROL DATA - R\& D.

(Security cleselfication of litlo, body of abstrect and indexine ennoletion must be entored whon the overall report le clasedlled,

U. S. Army Engineer Waterways Experiment Station

Vicksburg, Mississippi

Unclassified

2b. GROUP

3. REPOAT TITLE

RAYLEIGH-WAVE DISPERSION TECHNIQUE FOR RAPID SUBSURFACE EXPLORATION

4. OESCRIPTIVE NOTES (TyPe ol ropopt and Inclualve datee)

Final report

3. AU THOR(S) (FITOt nOmO, mIddIO InItIOI, leot nemo)

Frank K. Chang

Robert F. Ballard, Jr.

\begin{tabular}{|c|c|c|}
\hline $\begin{array}{l}\text { 6. REPOAT OATE } \\
\text { April } 1973 \\
\end{array}$ & $\begin{array}{c}\text { 7a. TOTAL NO. OF PAGES } \\
29 \\
\end{array}$ & $\begin{array}{c}\text { 76. NO. OF REF S } \\
5\end{array}$ \\
\hline $\begin{array}{l}\text { O.. CONTRACT OR GRANTNO. } \\
\text { B. PROJECT NO. }\end{array}$ & $\begin{array}{r}\text { 20. ORIGINATOA'S REPORT } \\
\text { MiscellaneOU: }\end{array}$ & per $S-73-20$ \\
\hline c. & $\begin{array}{l}\text { DD. OTHER REPORT NO(S) } \\
\text { (hio roport) }\end{array}$ & ther numbere that may bo aediened \\
\hline
\end{tabular}

10. DISTRIBUTION STATEMENT

Approved for public release; distribution unlimited.

\begin{tabular}{l|l}
\hline 11. SUPPLEMENTAnY NOTES Paper presented to & 12. SPONSORING MILITARY ACTIVITY \\
42d Annual International Meeting of the \\
Society of Exploration Geophysicists.
\end{tabular}

13. AOSTRACT This paper reports an investigation of improved or new techniques to extend the depth and/or resolution capability of rapid shallow-depth (less than 500 ft) explorations that would quickly and economically provide an engineer with accurate information on substrate conditions. Current geophysical techniques for rapidly exploring construction sites and investigating foundations, i.e., electrical resistivity, seismic refraction, and vibratory techniques, were reviewed for relative merits and shortcomings. By combining various attributes of the refraction seismic and vibratory techniques, it was considered feasible that a study of surface-wave phenomena could measurably extend the depth limits of current investigation techniques. As a result, the so-called "Rayleigh-wave dispersion technique" was envisioned as a potentially promising, in situ test method. A test program was formulated to adapt conventional refraction seismic equipment and field procedures to acquire Rayleigh-wave data. Theoretical considerations, test procedures, interpretation of data, and comparisons with data obtained by standard methods are presented. Various advantages and limitations of the Rayletgh-wave atspersion technique are discussed. 
Unclassified

Security Clasoification

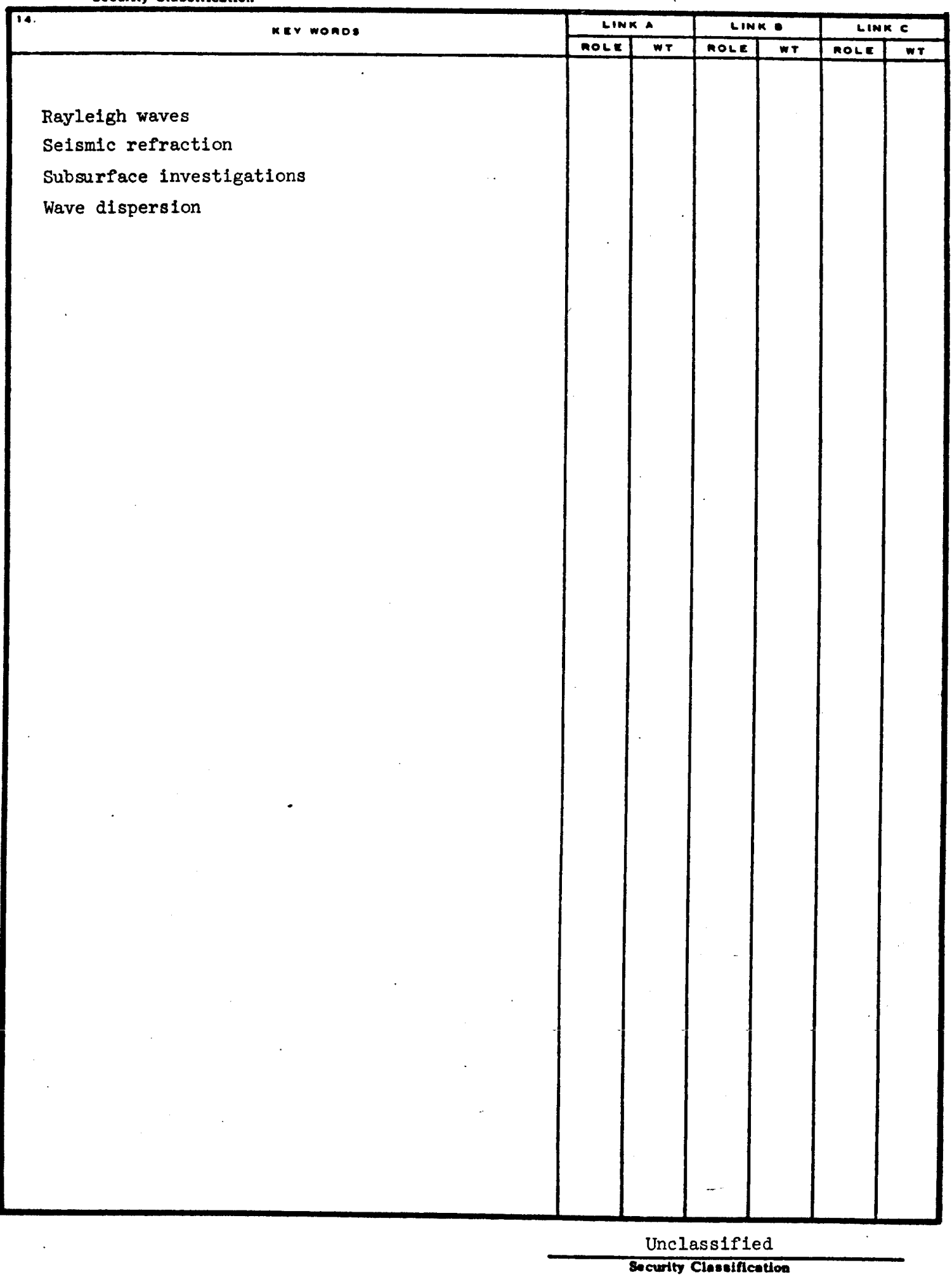

